\title{
Pioneers in lung research
}

$I^{\mathrm{t}}$

have to admit to being partial to biographies, particularly of scientists. When, in

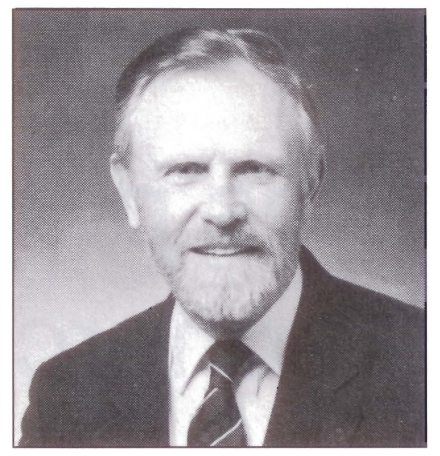

addition, the scientist's field is close to your own, this is an added bonus, once you have got over the initial reaction to what was achieved in years gone by with limited resources. What would they have achieved with the tools available to us now, is the usual question that comes to mind. For these reasons, I hope other contributors to the present issue of the Journal will forgive me for selecting Norman Staub's article on CC Macklin for special mention. It is easy to appreciate Dr Staub's evident relish as he approached the career of this pioneering Canadian researcher, for like Dr Staub he was fascinated with the structure-function relationships in human alveoli and the mechanisms of alveolar damage and edema. The result is a gem of medical historical writing and a portrait of two people, Charles Macklin and his wife Madge, as they attempt to be innovative in research and teaching in the face of academic bureaucracy. Dr Staub is now Professor Emeritus at the Cardiovascular Research Institute (CVRI) in San Francisco, where I first met him 30 years ago. Two reasons stand out for my clear memory of him then. First was his research into relationships between morphological and physiological events in lung studied by rapid freezing and the demonstration of alveolar duct constriction in embolized lungs, which appeared to account for the otherwise puzzling arterial desaturation following emboli. My second recollection relates to what was to trainees the most important event in the CVRI week: the Saturday morning meeting devoted to an assigned topic presented by fellows in front of Dr Comroe and other senior members of the staff. The reason it worked so well was that Dr Staub and his colleagues invariably came and were prepared to put their reputations on the line during the informal discussions that were a feature of the morning. It somehow made it easier for us fellows to survive Dr Comroe's daunting gaze. There are many Canadians in high academic positions who benefited from the experience of a year or three at the CVRI; all will remember Dr Staub's science, but his humour and generosity will dominate our recollections. After an interval of 30 years, and particularly for his portrait of a Canadian pioneer lung researcher, I can only say: Norman, thanks for everything!

Norman L Jones MD Editor-in-Chief Canadian Respiratory Journal 


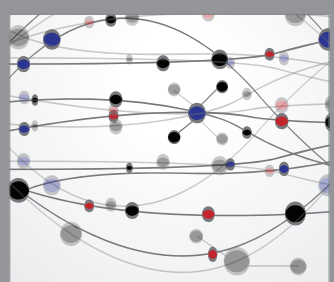

The Scientific World Journal
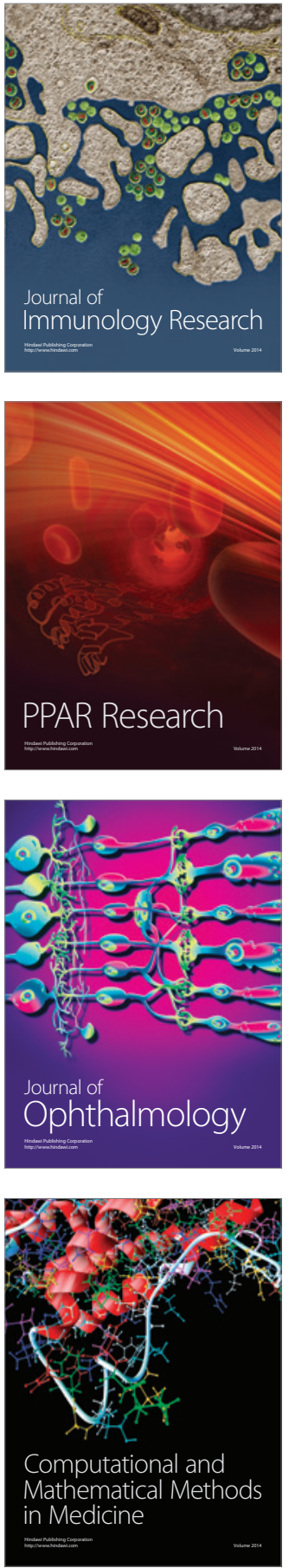

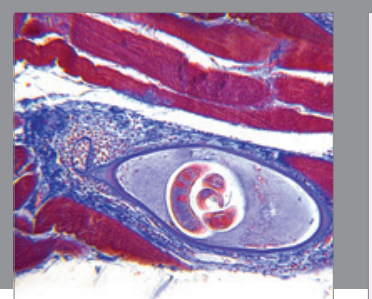

Gastroenterology Research and Practice

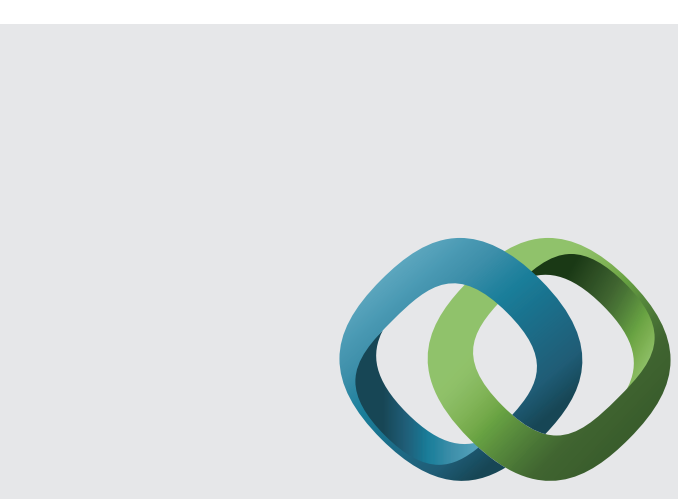

\section{Hindawi}

Submit your manuscripts at

http://www.hindawi.com
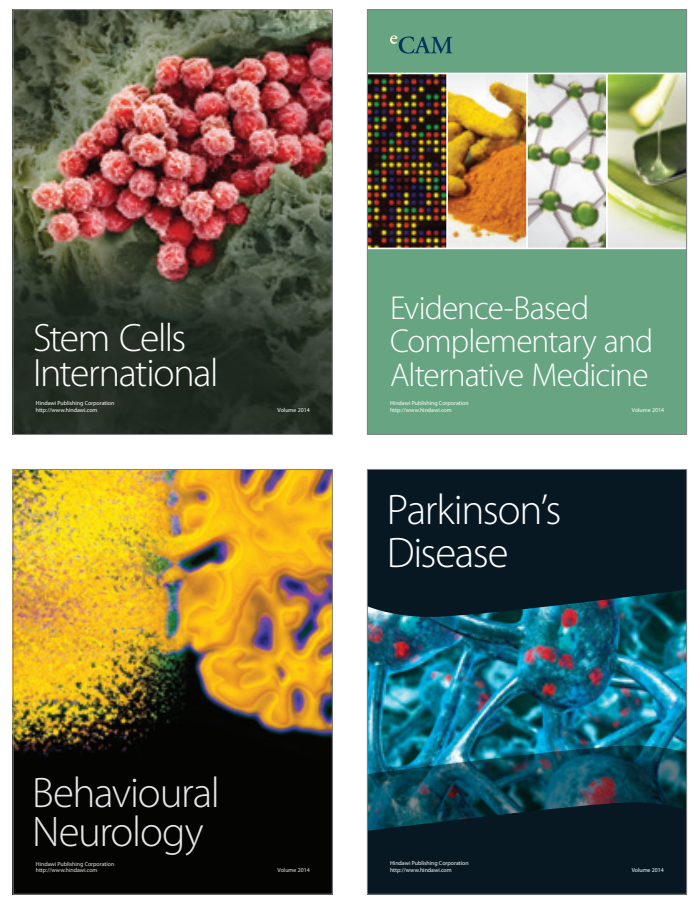
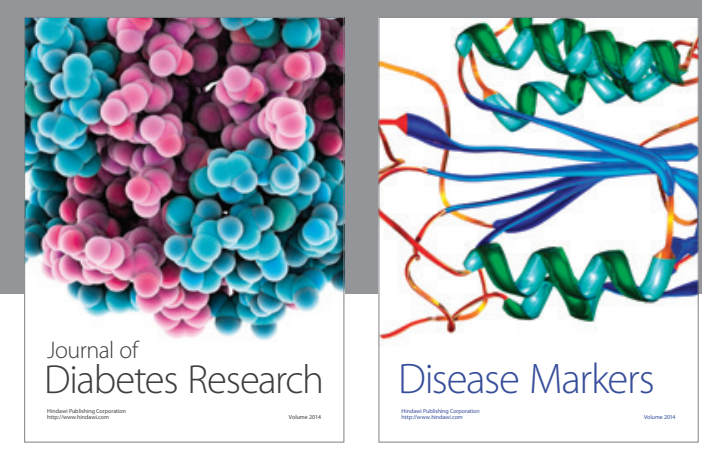

Disease Markers
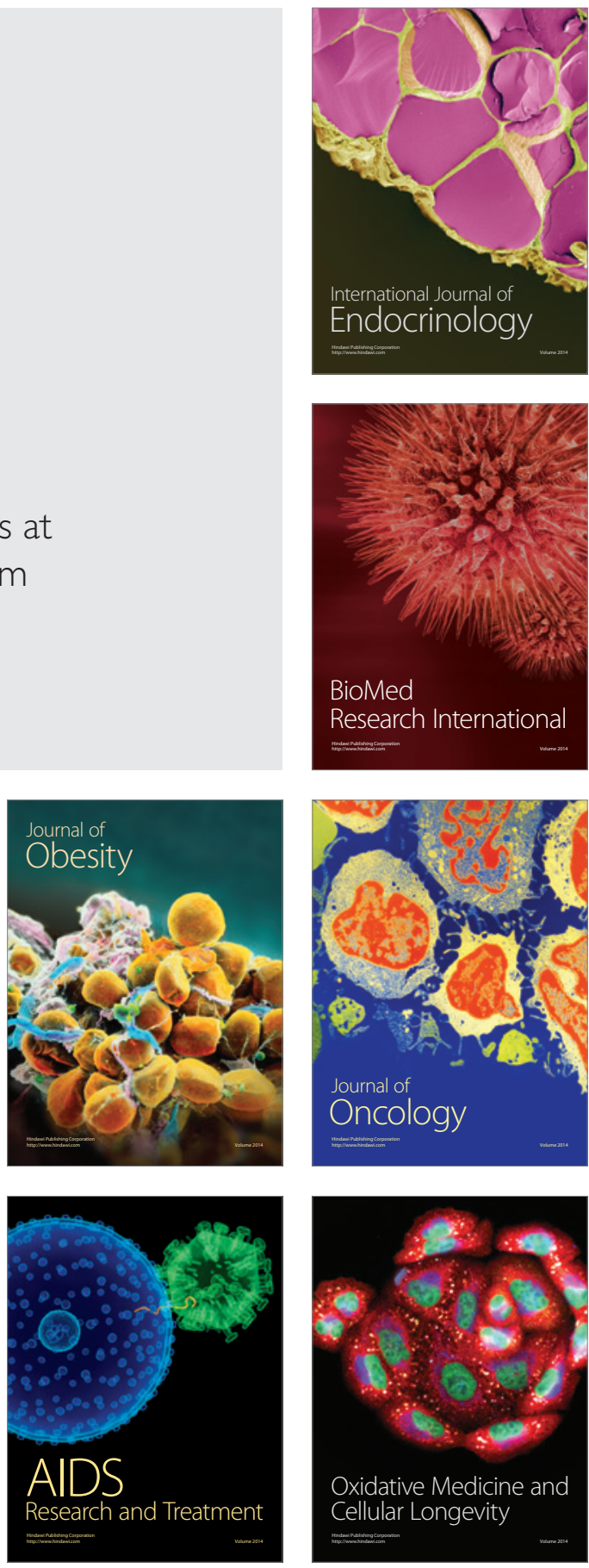